\title{
Deleterious RAD51B Gene Mutation
}

National Cancer Institute

\section{Source}

National Cancer Institute. Deleterious RAD51B Gene Mutation. NCI Thesaurus. Code C134504.

A change in the nucleotide sequence of the RAD51B gene that is associated with increased risk of disease. 